\title{
Selective $N$-cycle hydrogenation of quinolines with sodium borohydride in aqueous media catalyzed by hectorite-supported ruthenium nanoparticles
}

\author{
Bing Sun, Diego Carnevale, Georg Süss-Fink* \\ Institut de Chimie, Université de Neuchâtel, CH-2000 Neuchâtel, Switzerland \\ Dedicated to Professor Heinrich Lang on the occasion of his $60^{\text {th }}$ birthday
}

\begin{abstract}
:
A new catalyst containing metallic ruthenium nanoparticles intercalated in hectorite (nanoRu'@hectorite) was found to catalyze the reduction of quinoline and quinoline derivatives by $\mathrm{NaBH}_{4}$ in aqueous solution to give selectively the corresponding 1,2,3,4-tetrahydroquinolines ( $N$-cycle hydrogenation). In most cases the reaction can be done under mild conditions (25-60 ${ }^{\circ} \mathrm{C}$ ) without pressure equipment, conversion and selectivity being superior to $99 \%$. In the case of sterically hindered derivatives, the reaction can be done in a pressure vessel under self-generated pressure (up to 9 bar). Isoquinoline and quinoxalines also undergo selective $N$-cycle hydrogenation, but 2-phenyl-quinoline is hydrogenated to give 2-phenyl-5,6,7,8-tetrahydroquinoline $(C$ cycle hydrogenation). Isotope labelling experiments combined with semi-empirical calculations of the electrostatic potentials support a heterolytic hydrogenation mechanism involving a hydride from $\mathrm{NaBH}_{4}$ and a proton from $\mathrm{H}_{2} \mathrm{O}$. The catalyst nanoRu'@ hectorite can be recycled and reused.
\end{abstract}

Keywords: Ruthenium nanoparticles; Hectorite; Quinoline derivatives; Quinoline analogues; Hydrogenation; Isotope labelling; Catalyst recycling

\footnotetext{
* Corresponding author. Tel.: +41 32 7182400; fax: +41327182511.

E-mail address: georg.suess-fink@unine.ch (G. Süss-Fink).
} 


\section{Introduction}

The hydrogenation of quinoline (Q) and its derivatives is a fascinating area of research, since the hydrogenation products such as 1,2,3,4-tetrahydroquinoline (THQ) have various industrial applications ranging from the production of petrochemicals and fine chemicals to the development of heterocyclic skeletons for pharmaceuticals and agrochemicals [1]. Synthetic methods to obtain THQ include catalytic cyclization [2-3], Beckman rearrangement [4] and the direct partial hydrogenation of quinoline. Among these methods, the $N$-cycle-selective hydrogenation of quinoline is the most interesting process because of its reasonable atom utilization efficiency. A general problem in the selective hydrogenation of $N$-cycles is, however, the possible and sometimes irreversible adsorption of the amine formed at the surface of the metal catalyst [5-6], thus blocking the catalytic sites.

Precious metal complexes can be used for the catalytic hydrogenation of quinoline to THQ, but most of these catalysts fail to give satisfactory results due to numerous complications associated with homogeneous catalysis [7-9]. Heterogeneous metal catalysts such as gold [10], palladium [11-13], rhodium [14-15], and ruthenium [16-18], supported on titania, alumina, silica, coal, hydroxyapatite or polymers have also been developed for this reaction. In most cases, elevated temperature and pressure are essential to convert quinoline into THQ, the selectivity being tuned by various organic solvents [19].

From the green chemistry point of view, water would be the most interesting solvent, because it is not only a green solvent in organic synthesis, but also plays a promoting role in enhancing the catalyst activity [20]. Only a few heterogeneous catalysts have been found active in the hydrogenation of quinoline in aqueous medium, such as ruthenium nanoparticles supported on silica spheres with an outer shell of microporous silica [21], palladium nanoparticles stabilized by black wattle tannin $[22,23]$ and palladium nanoparticles supported by polymers [24]. Notably, graphene-supported $\mathrm{Ru}$ or $\mathrm{Rh}$ nanoparticles are found to catalyze the hydrogenation of aromatics efficiently even without solvents $[25,26]$. 
In our previous work, we developed a heterogeneous catalyst by intercalation of cationic benzene ruthenium complexes into hectorite, followed by reduction with molecular hydrogen to give a black solid containing metallic ruthenium nanoparticles intercalated in hectorite (nanoRu@ hectorite) [27-29]. This material was found to catalyze the hydrogenation of quinoline with switchable selectivity, the reaction in water at $60{ }^{\circ} \mathrm{C}$ and 30 bar $\mathrm{H}_{2}$ giving THQ, conversion and selectivity being at 99\% [30]. However, high-pressure equipment is required for this reaction.

Inspired by a recent paper by M. M. Dell'Anna $e t$ al. on the hydrogenation of quinoline by sodium borohydride in water catalyzed by polymer-supported palladium nanoparticles [31], we modified our nanoRu@ @ectorite catalyst system, so that it also works with $\mathrm{NaBH}_{4}$ and $\mathrm{H}_{2} \mathrm{O}$ as the hydrogen source for the hydrogenation of quinoline. The simple intercalation of $\mathrm{RuCl}_{3} \cdot \mathrm{n}$ $\mathrm{H}_{2} \mathrm{O}$ in hectorite gives a black precatalyst, which is stable in air and which catalyzes the selective hydrogenation of quinoline to THQ with $\mathrm{NaBH}_{4}$ in water under mild conditions in an open reaction vessel; no pressure equipment is required. The actual catalyst, metallic ruthenium nanoparticles intercalated in hectorite (nanoRu'@ hectorite), can be recovered and reused. Herein, we report the preparation of the precatalyst, the characterization of the catalyst and its performance for $\mathrm{N}$-cycle hydrogenation of quinoline and its derivatives including isoquinoline and quinoxalines.

\section{Experimental}

\subsection{General}

Deionized water was made from tap water by ionic exchange resins and degassed before use. All the $N$-cyclic chemicals were purchased from commercially available sources and used as received. $\mathrm{RuCl}_{3} \cdot \mathrm{n} \mathrm{H}_{2} \mathrm{O}$ was loaned by the Johnson Matthey Research Centre. $\mathrm{NaBH}_{4}$ and $\mathrm{NaBD}_{4}$ (D, 98 atom \%) were purchased from Aldrich, and $\mathrm{D}_{2} \mathrm{O}$ (D, 99.9\%) from Cambridge Isotope Laboratories.

\subsection{Preparation of the precatalyst}


White sodium hectorite powder was synthesized according to the method of Bergk and Woldt [32]. The sodium cation exchange capacity, determined under the method of Lagaly and Tributh [33], was found to be $1.04 \mathrm{mEq} / \mathrm{g}$. White hectorite powder (1 g) was degassed in vacuo for $1 \mathrm{~h}$ and followed by the $\mathrm{N}_{2}$ saturation, then the calculated amount of $\mathrm{RuCl}_{3} \cdot \mathrm{n} \mathrm{H}_{2} \mathrm{O}(0.40$ mmol) dissolved in $85 \mathrm{ml} \mathrm{H}_{2} \mathrm{O}$ (black solution) was transferred dropwise to the hectorite powder. The suspension was stirred for $3 \mathrm{~h}$ at room temperature, then treated by filtration and washing with deionized $\mathrm{H}_{2} \mathrm{O}$ (black solid) until no chloride ion was detected. The obtained solid product was dried in vасио at $50{ }^{\circ} \mathrm{C}$ for $12 \mathrm{~h}$ and then ground to give a fine powder, containing 0.39 $\mu \mathrm{mol} / \mathrm{mg} \mathrm{Ru}(2 \mathrm{~mol} \%)$ based on ICP-OES analysis.

\subsection{Characterization of the catalyst nanoRu'@hectorite formed in situ during the catalytic hydrogenation reactions}

The powder X-ray diffraction (PXRD) patterns of the catalysts were collected by XRD Application LAB in CSEM (Switzerland). The samples were measured in air at $20{ }^{\circ} \mathrm{C}$ on a STOE STADIP high-resolution X-ray diffractometer using $\mathrm{CuK} \alpha$ radiation. D-spacing (d) determination of the interlamellar spacing in hectorite, based on hectorite (001) reflection, was calculated from Bragg's law [34]:

$$
\mathrm{n} \lambda=2 \mathrm{~d} \sin \theta
$$

where $\mathrm{n}$ is an integer (herein $\mathrm{n}=1$ ), $\lambda$ is the X-ray wavelength (for the CuK $\alpha, \lambda=1.5418 \AA$ ). $\theta$ is the angle between incident beam and scattering planes.

Transmission electron microscopy (TEM) was conducted in CSEM on a Philips CM 200 Transmission Electron Microscope (operating at $200 \mathrm{kV}$ ) coupled with Energy Dispersive X-ray spectrometry (EDS) for chemical analysis. The solid catalyst samples are thoroughly dispersed in ethanol and deposited on carbon film coated square mesh copper grids. The calculation of the nanoparticle size was obtained from TEM images with a number of over 100 nanoparticles by using the software ImageJ [35]. 
Inductively coupled plasma optical emission spectrometry (ICP-OES, Perkin-Elmer Optima 3300 DV) was employed to analyze the amount of in situ formed ruthenium in hectorite and ruthenium leaching in the centrifuged supernatant after the catalytic run.

\subsection{Catalytic reactions}

Precatalyst (50 mg), $\mathrm{NaBH}_{4}$ (or $\left.\mathrm{NaBD}_{4}\right)(3-12 \mathrm{mmol}), 1 \mathrm{mmol}$ of the $N$-cyclic substrate and $5 \mathrm{ml}$ deionized and degassed water (or $\mathrm{D}_{2} \mathrm{O}$ ) were placed in a $25 \mathrm{ml}$ three-necked flask equipped with a reflux condenser and a pressure release valve to discharge the hydrogen gas self-generated during the reactions. The operation was carried out under inert atmosphere. The reaction mixture was vigorously stirred at different temperatures $\left(25-60{ }^{\circ} \mathrm{C}\right)$ for the time selected. The complete conversion of substrate was determined by submitting small samples to spot thin layer chromatography (TLC). After completion, the slurry was centrifuged to separate the catalyst. The solid phase obtained was washed with deionized $\mathrm{H}_{2} \mathrm{O}$ and then several times with ethyl acetate to remove all organic residue. The filtrate was collected, extracted with ethyl acetate and the extract dried over anhydrous $\mathrm{MgSO}_{4}$. After removal of the solvent in vacuo, the corresponding product was obtained. In some cases, a silica-gel column chromatography was used to purify the product (isolated yield). The product analysis and identification was conducted by comparing the NMR spectral data with those of the published pure substances (all analyzed by ${ }^{1} \mathrm{H}$ NMR and ${ }^{13} \mathrm{C}$ NMR on Bruker Avance II $400 \mathrm{MHz}$ spectrometer). The reaction selectivities were obtained from the NMR spectra by integration of characteristic peaks for the product and reactant.

Alternatively, the reaction was performed in a magnetically stirred stainless-steel autoclave $(100 \mathrm{ml})$ in cases where the reaction failed to be complete under atmospheric pressure. The loading procedure was the same as that in a flask. After purging three times with nitrogen, the autoclave was quickly fixed in the preheated oil bath. Once the reaction was complete, the autoclave was quenched in cold water, the pressure was released, and the product was isolated as described above.

Isotope labeling experiments were done for the hydrogenation of quinoline with $\mathrm{NaBH}_{4} /$ $\mathrm{D}_{2} \mathrm{O}$ and with $\mathrm{NaBD}_{4} / \mathrm{H}_{2} \mathrm{O}$ (and for comparison with $\mathrm{NaBH}_{4} / \mathrm{H}_{2} \mathrm{O}$ and with $\mathrm{NaBD}_{4} / \mathrm{D}_{2} \mathrm{O}$ ), under the same conditions as those of entry 7 in Table 1 (see below). All NMR spectra were recorded 
with a narrow-bore Bruker 400 spectrometer $\left(9.4 \mathrm{~T}\right.$ ) operating at $\omega_{0} / 2 \pi=400.0$ and $100.6 \mathrm{MHz}$ for ${ }^{1} \mathrm{H}$ and ${ }^{13} \mathrm{C}$, respectively, and equipped with an AVANCE-II console and a $5 \mathrm{~mm}$ doubleresonance probe. The $r f$-field strengths of all hard $\pi / 2$ and $\pi$ pulses were $\omega_{1} / 2 \pi=26 \mathrm{kHz}$ and 27 $\mathrm{kHz}$, for ${ }^{1} \mathrm{H}$ and ${ }^{13} \mathrm{C}$ channels, respectively. Quantitative proton spectra were acquired with a recycling delay $d_{1}=5 \times T_{1}$, with longitudinal relaxation time constraints $T_{1}$ of the as measured inversion-recovery experiments. Semi-empirical calculations were performed with the PM7 method as implemented in MOPAC2012 [36]. The optimized geometries were used for calculations of the electrostatic potentials by means of the keyword ESP.

The recyclability of the nanoRu'@hectorite catalyst was examined for the hydrogenation of quinoline under atmospheric pressure in a flask. After a catalytic run, the catalyst was recovered by centrifugation and purified by washing with deionized $\mathrm{H}_{2} \mathrm{O}$ and ethyl acetate and dried in vacuo at room temperature for $12 \mathrm{~h}$. Then the recycled catalyst was used for the next catalytic run without any reactivation.

\section{Results and discussion}

\subsection{Characterization of the catalyst nanoRu' @ hectorite}

The nanoRu'@hectorite precatalyst is accessible from synthetic sodium hectorite, a white solid presenting an idealized cell formula of $\mathrm{Mg}_{5.5} \mathrm{Li}_{0.5} \mathrm{Si}_{8} \mathrm{O}_{20}(\mathrm{OH})_{4} \mathrm{Na} \cdot n \mathrm{H}_{2} \mathrm{O}$ [37] and an aqueous solution of $\mathrm{RuCl}_{3} \cdot \mathrm{n} \mathrm{H}_{2} \mathrm{O}$. The black material is obtained by ion exchange of the sodium cations against ruthenium(III) aqua cations in the interlaminar space. The d-spacing $\left(d_{001}\right)$ of the sodium hectorite and $\mathrm{Ru}(\mathrm{III})$-containing hectorite are $13.4 \AA$ and $15.2 \AA$, respectively (Figure 1). The enlarged interlaminar space can be attributed to the actual intercalation of ruthenium(III) aqua cations. The black $\mathrm{Ru}(\mathrm{III})$-containing catalyst precursor is stable in air and can be isolated and stored. When suspended in water, this precatalyst can be reduced by $\mathrm{NaBH}_{4}$ to give the activenanoRu'@hectorite catalyst, an air-sensitive black powder with a d-spacing of $13.6 \AA$, while the d-spacing of the in situ formed nanoRu'@hectorite catalyst after a catalytic run is 13.7 $\AA$. The similar d-spacing for the sodium-containing hectorite and nanoRu'@hectorite suggests that the ruthenium nanoparticles are thoroughly embedded in the interlayers of the hectorite. 
Besides, a visible $\mathrm{Ru}(011)$ peak was observed only for the nanoRu'@hectorite reduced in pure water, suggesting a larger particle size as compared to the in situ formed nanoRu'@hectorite in a water/quinoline mixture.

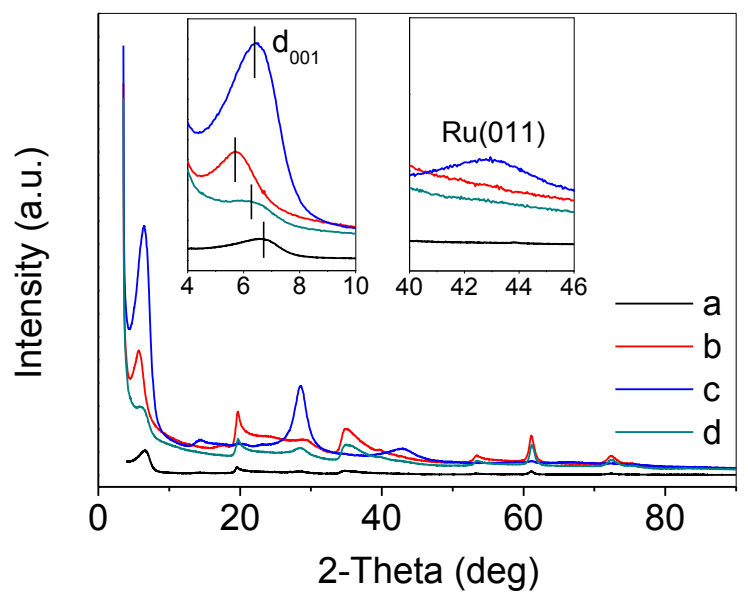

Fig. 1. Powder X-ray diffraction (PXRD) patterns of the samples of (a) the sodium-containing hectorite powder, (b) the $\mathrm{Ru}(\mathrm{III})$-containing hectorite (precatalyst), (c) the nanoRu'@ hectorite reduced by $\mathrm{NaBH}_{4}$ at $60{ }^{\circ} \mathrm{C}$ for 4 $\mathrm{h}$ in water under atmospheric pressure without organic agent and (d) the in situ generated nanoRu'@hectorite after a fresh run for the catalytic hydrogenation of quinoline under atmospheric pressure at $60{ }^{\circ} \mathrm{C}$ for $4 \mathrm{~h}$ in water. The $d_{001}$ of these samples are calculated to be $13.4 \AA$, $15.2 \AA, 13.6 \AA$ and $13.7 \AA$, respectively. The insets are the zoomed XRD patterns for clarity.

The morphology of the metallic ruthenium nanoparticles imbedded in the hectorite interlayers of nanoRu'@ hectorite was studied by transmission electron microscopy. The reduction of transition metal salts by sodium borohydride is a common method for the preparation of metallic nanoparticles that allows a certain control of the morphology, important for activity and selectivity for catalytic applications [38]. The reaction medium (organic solvents or water) is also decisive for the morphology of the nanoparticles [29, 39, 40]. Figure 2 shows the TEM images of nanoRu'@hectorite obtained under different conditions: The ruthenium nanoparticles formed by sodium borohydride reduction of the precatalyst in pure water without a substrate being present is depicted in Figure 2a, while Figure $2 \mathrm{~b}$ shows the in situ generated ruthenium nanoparticles 
obtained during a catalytic run in aqueous solution from the precatalyst and sodium borohydride in the presence of quinoline as the substrate. The recycled nanoRu'@ hectorite catalyst after the second catalytic run for the hydrogenation of quinoline is depicted in Figure 2c. In all cases, ruthenium is present in the form of nanoparticles the size of which varies between 1 and $10 \mathrm{~nm}$. In pure water, without an organic substrate being present, the ruthenium nanoparticles (mean size $4.5 \mathrm{~nm}$ ) agglomerate to give worm-like structures, a similar morphology to that observed for ruthenium nanoparticles supported on cetyltrimethylammonium bromide (CTAB) modified montmorillonite [17]. However, the in situ formed ruthenium nanoparticles in the presence of quinoline are smaller (mean size $2.4 \mathrm{~nm}$ ) and agglomerate to spherical clusters of a diameter of $28.1 \mathrm{~nm}$ (average); this is also observed for the recycled nanoRu'@hectorite catalyst, where the ruthenium nanoparticles (mean $2.1 \mathrm{~nm}$ ) are slightly smaller, while the spherical agglomerates (mean $41.3 \mathrm{~nm}$ ) are slightly larger. The observed particle size is consistent with that calculated from PXRD analysis. 
(a)
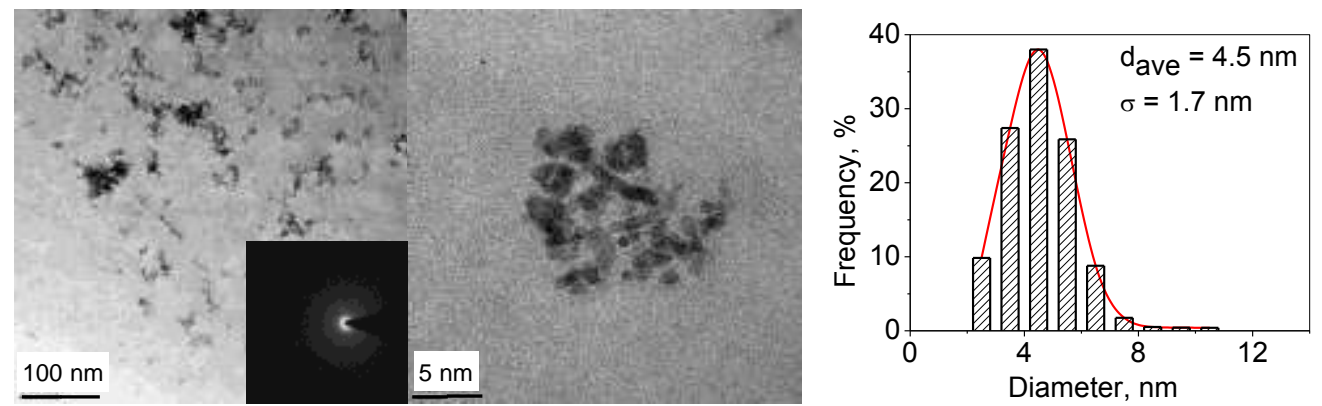

(b)
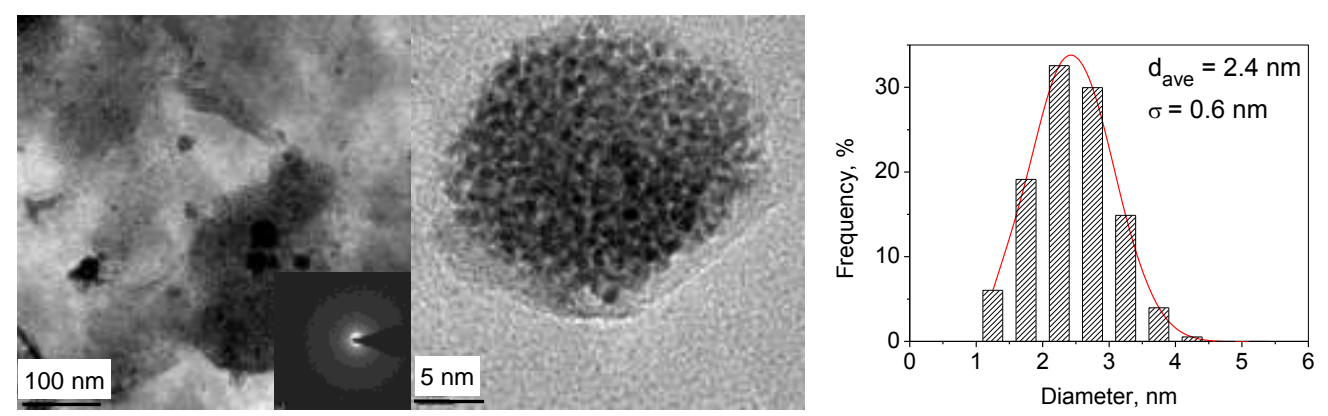

(c)
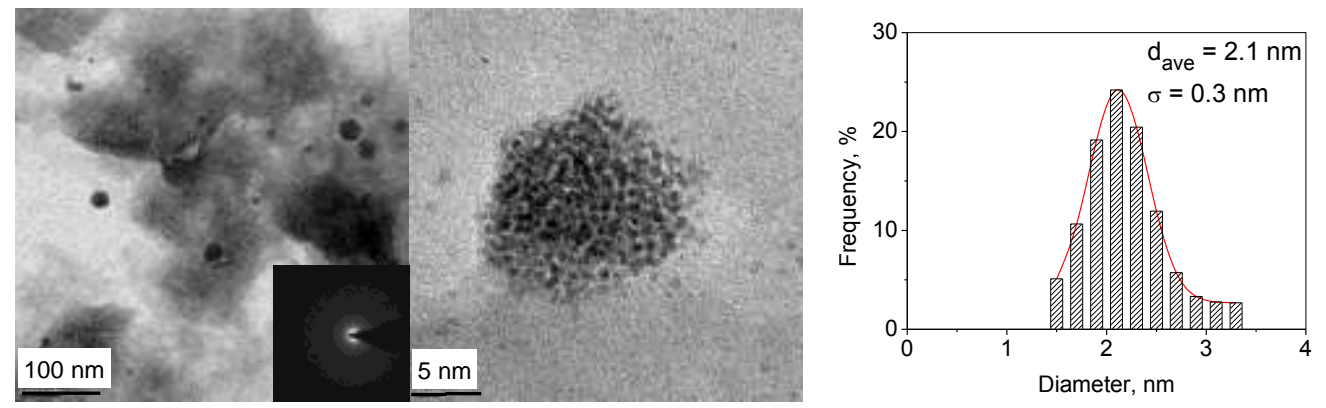

Fig. 2. Transmission electron micrographs of the samples of (a) nanoRu'@hectorite from the reduction of the precatalyst by $\mathrm{NaBH}_{4}$ under atmospheric pressure at $60{ }^{\circ} \mathrm{C}$ for $4 \mathrm{~h}$ in water without organic agent, (b) the in situ generatednanoRu'@hectorite catalyst after a fresh run for the catalytic hydrogenation of quinoline under atmospheric pressure at $60^{\circ} \mathrm{C}$ for $4 \mathrm{~h}$ in water and (c) the nanoRu'@ run for the hydrogenation of quinoline under atmospheric pressure at $60{ }^{\circ} \mathrm{C}$ for $4 \mathrm{~h}$ in water.

\subsection{Catalytic hydrogenation of quinoline}

To optimize the reaction parameters, the hydrogenation of quinoline was studied by using different solvents and various amounts of $\mathrm{NaBH}_{4}$ in a flask under atmospheric pressure and also in an autoclave under self-generated pressure depending on the amount of $\mathrm{NaBH}_{4}$. In catalytic hydrogenation reactions, the solvent plays an important role in influencing the reaction rate and 
selectivity [19, 41, 42]. As shown in Table 1, several common organic solvents and $\mathrm{H}_{2} \mathrm{O}$ have been tested into the hydrogenation under different conditions. The best results were obtained with $\mathrm{H}_{2} \mathrm{O}$ as solvent. Besides the difference in the nature of the solvents, the poor solubility of $\mathrm{NaBH}_{4}$ in aprotic polar solvent (such as THF) and the decomposition of $\mathrm{NaBH}_{4}$ in protic solvents, especially in methanol, can be considered to be the reason of the observed low reactivity. Moreover, $\mathrm{H}_{2} \mathrm{O}$ as a solvent has been frequently observed to be a promoter in stimulating the hydrogenation rate $[21,24,30]$. In the present work, the selective hydrogenation of $\mathbf{1}$ into $\mathbf{1 a}$ was successfully conducted in $\mathrm{H}_{2} \mathrm{O}$ under atmospheric pressure in a flask (entry 7, Table 1), and under self-generated pressure in the autoclave (entry 12, Table 1). However, for the reaction in a flask, a higher amount of $\mathrm{NaBH}_{4}$ was necessary to attain complete conversion of $\mathbf{1}$.

Table 1

Hydrogenation of quinoline (1) to 1,2,3,4-tetrahydroquinoline (1a) by $\mathrm{NaBH}_{4}$ catalyzed by nanoRu'@hectorite.

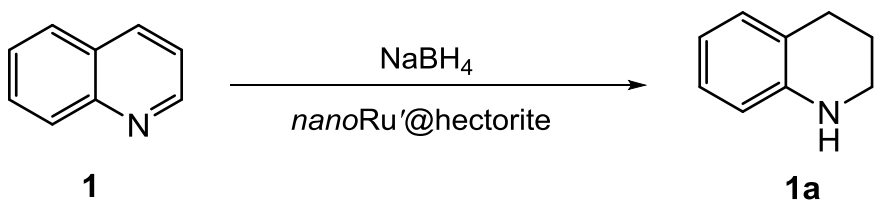

\begin{tabular}{|c|c|c|c|c|c|c|c|c|c|}
\hline Entry & Solvent ${ }^{\mathrm{a}}$ & $\mathrm{Q} / \mathrm{M}^{\mathrm{b}}$ & $H / Q^{c}$ & $\mathrm{~T},{ }^{\circ} \mathrm{C}$ & $p$, bar & $\mathrm{t}, \mathrm{h}$ & $\mathrm{C}, \%^{\mathrm{d}}$ & $\mathrm{S}, \%^{\mathrm{e}}$ & TOF $^{f}$ \\
\hline 1 & $\mathrm{MeOH}$ & 50 & 12 & 60 & a.p. ${ }^{\mathrm{g}}$ & 6 & $<5$ & 99 & $<0.4$ \\
\hline 2 & $\mathrm{EtOH}$ & 50 & 12 & 60 & a.p..$^{g}$ & 6 & 12 & 99 & 1 \\
\hline 3 & THF & 50 & 12 & 60 & a.p..$^{\mathrm{g}}$ & 6 & 10 & 99 & 0.8 \\
\hline 4 & $\mathrm{H}_{2} \mathrm{O}$ & 50 & 8 & 40 & a.p. ${ }^{\mathrm{g}}$ & 20 & 56 & 99 & 1.4 \\
\hline 5 & $\mathrm{H}_{2} \mathrm{O}$ & 50 & 10 & 60 & a.p. ${ }^{\mathrm{g}}$ & 4 & 95 & 99 & 11.9 \\
\hline 6 & $\mathrm{H}_{2} \mathrm{O}$ & 50 & 12 & 40 & a.p..$^{g}$ & 4 & 60 & 99 & 7.5 \\
\hline 7 & $\mathrm{H}_{2} \mathrm{O}$ & 50 & 12 & 60 & a.p. ${ }^{\mathrm{g}}$ & 4 & 99 & $99(95)$ & 12.4 \\
\hline 8 & $\mathrm{H}_{2} \mathrm{O}$ & 90 & 8 & 60 & a.p..$^{g}$ & 20 & 81 & 99 & 3.6 \\
\hline 9 & $\mathrm{H}_{2} \mathrm{O}$ & 90 & 14 & 60 & a.p..$^{g}$ & 20 & 92 & 99 & 4.1 \\
\hline 10 & $\mathrm{H}_{2} \mathrm{O}$ & 90 & 20 & 60 & a.p. ${ }^{\mathrm{g}}$ & 20 & 98 & 99 & 4.4 \\
\hline $11^{\mathrm{h}}$ & $\mathrm{H}_{2} \mathrm{O}$ & 50 & 8 & 40 & 5 & 5 & 85 & 99 & 8.5 \\
\hline
\end{tabular}




\begin{tabular}{llllllllll}
$12^{\mathrm{h}}$ & $\mathrm{H}_{2} \mathrm{O}$ & 50 & 8 & 60 & 9 & 3 & 99 & 99 & 16.5 \\
\hline
\end{tabular}

${ }^{\text {a }}$ Solvent volume $5 \mathrm{ml}$.

${ }^{\mathrm{b}}$ Molar ratio of quinoline to ruthenium. The precatalyst was used unless stated otherwise.

${ }^{\mathrm{c}}$ Molar ratio of $\mathrm{NaBH}_{4}$ to quinoline.

${ }^{\mathrm{d}}$ Conversion of quinoline.

${ }^{\mathrm{e}}$ Selectivity for THQ, the value in the parentheses being the isolated yield.

${ }^{\mathrm{f}} \mathrm{TOF}$ is defined as the mole of the converted quinoline per mole Ru per hour.

${ }^{g}$ Atmospheric pressure.

${ }^{\mathrm{h}}$ Carried out in a pressure vessel, the corresponding pressure being the self-generated pressure.

Throughout all the tests listed in Table 1, the hydrogenation of $\mathbf{1}$ into $\mathbf{1 a}$ was complete under atmospheric pressure or under self-generated pressure of molecular $\mathrm{H}_{2}$, both the conversion and selectivity being up to $99 \%$. In comparison with the Pd-pol catalyst [31], less $\mathrm{NaBH}_{4}$ (only an 812-fold molar excess) was required with nanoRu'@ hectorite as catalyst. In the blank experiments without catalyst, the conversion was only $51-53 \%$, indicating that the catalyst is essential for the quantitative conversion of $\mathbf{1}$. A higher amount of $\mathrm{NaBH}_{4}$ (20-fold molar excess) generates dihydroquinoline and azo compounds as by-products [31].

\subsection{Catalytic $N$-cycle hydrogenation of quinoline derivatives and analogues}

Since nanoRu'@hectorite has been found active for the hydrogenation of quinoline, the optimized conditions were applied for the hydrogenation of quinoline derivatives and analogues. As depicted in the Table 2, several quinoline derivatives and analogues were successfully hydrogenated to the corresponding products shown. It should be noted that sometimes a small amount of an organic co-solvent (ethanol or dimethylformamide) was used to improve the solubility of the organic reagents. In entries 1-3 of Table 2, 8-methylquinoline (2) and 6-methylquinoline (3) were efficiently hydrogenated. Under atmospheric pressure, $\mathbf{3}$ was exclusively transformed into 6-methyl-tetrahydroquinoline (3a); however, 2 was only partly hydrogenated to $2 \mathbf{a}$ with a maximum conversion of $53 \%$ even after $24 \mathrm{~h}$. This may be explained by the steric effect of the 8 methyl substituent on the nucleophilic attack of the hydride to the $\mathrm{C}=\mathrm{N}$ bond or by hyperconjugation [31, 43]. Interestingly, a self-generated pressure (3 bar $\left.\mathrm{H}_{2}\right)$ remarkably 
improved the hydrogenation of $\mathbf{2}$, which was complete in $3 \mathrm{~h}$ even at room temperature $\left(25^{\circ} \mathrm{C}\right)$. For comparison, the quinoline hydrogenation was done under the same conditions as those for $\mathbf{2}$, but only a low conversion was observed, suggesting that, under a certain pressure, the electrondonating 8-methyl group is favorable for the hydride transfer to the $N$-cycle. Throughout all the results for the hydrogenation of $\mathbf{1 , 2}$ and $\mathbf{3}$, it can be concluded that the electronic influence exerted by the substituents plays a crucial role in affecting the reactivity. A similar phenomenon was observed in the hydrogenation of $\mathbf{2}$ and $\mathbf{3}$ by a platinum oxide catalyst [44].

\section{Table 2}

Hydrogenation of $N$-cycles (substrates 2-10) catalyzed by nanoRu'@hectorite in aqueous medium

Entry ${ }^{\mathrm{a}}$


10<smiles>Cc1cnc2ccccc2n1</smiles>

8

$11^{\mathrm{h}}$

$12^{\mathrm{h}}$<smiles>Oc1ccc(Cl)c2cccnc12</smiles>

9

$13^{\mathrm{g}}$

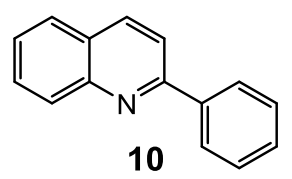<smiles>CC1CNc2ccccc2N1</smiles>

$8 \mathbf{a}$<smiles>Oc1ccc(Cl)c2c1CCCN2</smiles>

$9 a$

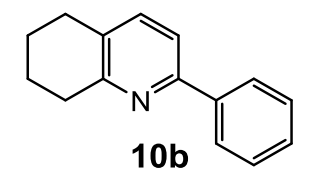

12

60

a.p.

8

77

99

4.8

$8 \quad 6$

60

9

3

99

99

16.5

60

$9 \quad 4 \quad 97$

98

${ }^{\text {a }} \mathrm{H}_{2} \mathrm{O}(5 \mathrm{~mL})$ as solvent, the molar ratio of substrate to ruthenium being 50 . The precatalyst was used.

${ }^{\mathrm{b}}$ Molar ratio of $\mathrm{NaBH}_{4}$ to substrate.

${ }^{\mathrm{c}}$ The atmospheric pressure (a.p.) in the flask, and the self-generated pressure in the autoclave.

${ }^{\mathrm{d}}$ Conversion of the $N$-cycle substrate.

e Selectivity for the product shown, the value in the parentheses being the isolated yield.

${ }^{\mathrm{f}}$ TOF is defined as the mole of the converted $N$-cycle substrate per mole Ru per hour.

${ }^{\mathrm{g}}$ Ethanol/ $\mathrm{H}_{2} \mathrm{O}(1 \mathrm{~mL} / 4 \mathrm{~mL})$ as solvent.

${ }^{\mathrm{h}}$ Dimethylformamide/ $\mathrm{H}_{2} \mathrm{O}(1 \mathrm{~mL} / 4 \mathrm{~mL})$ as solvent.

The catalytic hydrogenation of 2,6-dimethylquinoline (4) did not work under atmospheric pressure, even in the presence of ethanol $(1 \mathrm{~mL})$ to dissolve the solid substrate. However, the hydrogenation of 4 to $4 \mathbf{a}$ worked under self-generated pressure of 6 bar at $60{ }^{\circ} \mathrm{C}$ in the autoclave (entry 5, Table 2). The conversion of 4 reached $99 \%$ after 4 hours; however, the maximum selectivity to $\mathbf{4 a}$ was only $88 \%$, the by-product being the $C$-cycle-hydrogenated quinoline. This may be attributed to the steric hindrance of the 2-methyl group [19, 24, 45]. Another challenging substrate is 8-hydroxyquinoline, for which there was no conversion under atmospheric pressure; the reaction only occurred in the autoclave at $60{ }^{\circ} \mathrm{C}$ (entry 7, Table 2). Isoquinoline (6) and quinoxalines (7-8) also underwent selective $N$-cycle hydrogenation (entry 8-10, Table 2). 5Chloro-8-quinolinol (9) was successfully converted into 5-chloro-1,2,3,4-tetrahydro-8-quinolinol (9a) (entry 12, Table 2). However, 2-phenyl-quinoline (10) was hydrogenated to give 2-phenyl5,6,7,8-tetrahydroquinoline $(\mathbf{1 0 b})$, see entry 13 in Table 2 ( $C$-cycle hydrogenation). This result 
shows that blocking $\mathrm{C}(2)$ by a phenyl substituent encumbers the hydrogenation of the $N$-cycle, suggesting that the attack of the hydride occurs at this carbon atom.

\subsection{Isotope labeling studies}

Sodium borohydride is a convenient reducing agent commonly used in organic synthesis for hydrogenation reactions. Although it undergoes rapid methanolysis with methanol to give molecular hydrogen, sodium hydroxide and trimethylborate, the hydrolysis in water is kinetically blocked, so that $\mathrm{NaBH}_{4}$ is inert in water and can be handled in aqueous solution [46]; however, it is susceptible to a slow $\mathrm{H} / \mathrm{D}$ exchange in $\mathrm{D}_{2} \mathrm{O}$ under acidic conditions [47].

In order to find out if sodium borohydride is the single hydrogen source for the hydrogenation of the $\mathrm{N}$-cycle in quinoline or if water is also involved, we carried out the catalytic reaction with $\mathrm{NaBH}_{4}$ in $\mathrm{H}_{2} \mathrm{O}$, with $\mathrm{NaBD}_{4}$ in $\mathrm{H}_{2} \mathrm{O}$, with $\mathrm{NaBH}_{4}$ in $\mathrm{D}_{2} \mathrm{O}$ and with $\mathrm{NaBD}_{4}$ in $\mathrm{D}_{2} \mathrm{O}$ and studied the deuteration of the product by NMR spectroscopy. Table 3 shows the assignment of ${ }^{13} \mathrm{C}$ and ${ }^{1} \mathrm{H}$ resonances of THQ in a $\mathrm{CDCl}_{3}$ obtained by Heteronuclear Single Quantum Coherence Spectroscopy (HSQC) and Heteronuclear Multiple Bond Correlation (HMBC) spectra. Based on the confirmed resonances, we could carry out the study over a comparison of the compounds containing deuterium at their different positions. The analysis is not easy, since the situation is complicated by a possible (acid-catalyzed) $\mathrm{H} / \mathrm{D}$ exchange between the $\mathrm{BH}_{4}{ }^{-}$anion and $\mathrm{D}_{2} \mathrm{O}$ (or the $\mathrm{BD}_{4}{ }^{-}$anion and $\mathrm{H}_{2} \mathrm{O}$ ) [47] and by the observed $\mathrm{H} / \mathrm{D}$ exchange of the $\mathrm{C}-\mathrm{H}$ and $\mathrm{N}-\mathrm{H}$ functions in the product 1,2,3,4-tetrahydroquinoline, even in the $C$-cycle.

\section{Table 3}

Assignment of ${ }^{13} \mathrm{C}$ and ${ }^{1} \mathrm{H}$ resonances of THQ in a $\mathrm{CDCl}_{3}$ obtained by HSQC and $\mathrm{HMBC}$ spectra

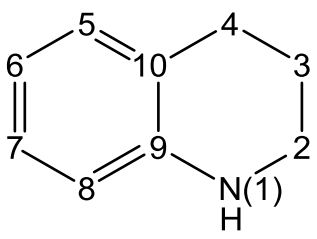

\begin{tabular}{lll}
\hline${ }^{13} \mathrm{C}(\mathrm{ppm})$ & ${ }^{1} \mathrm{H}(\mathrm{ppm})$ & Assignment \\
\hline
\end{tabular}




\begin{tabular}{lcc}
\hline 114.86 & - & 9 \\
129.58 & 7.00 & 5 \\
126.79 & 7.02 & 7 \\
121.49 & - & 10 \\
116.98 & 6.66 & 6 \\
114.25 & 6.52 & 8 \\
42.06 & 3.35 & 2 \\
27.06 & 2.82 & 4 \\
22.26 & 2.00 & 3 \\
\hline
\end{tabular}

Figure 3 shows that a pure $\mathrm{CH}_{2}$ sample may be produced when no deuterium is supplied to the reaction. A mixture of $\mathrm{CH}_{2}$ and $\mathrm{CHD}$ groups needs to be taken into account, as soon as ${ }^{2} \mathrm{H}$ nuclei are involved in the reduction process, either as $\mathrm{NaBD}_{4}$ or $\mathrm{D}_{2} \mathrm{O}$, and when no protic hydrogen is supplied, only CHD groups are obtained. In the cases of $\mathrm{NaBH}_{4} / \mathrm{D}_{2} \mathrm{O}$ and $\mathrm{NaBD}_{4} / \mathrm{H}_{2} \mathrm{O}$, when both $\mathrm{CH}_{2}$ and $\mathrm{CHD}$ are present, ${ }^{13} \mathrm{C}\left\{{ }^{1} \mathrm{H}\right\}$ and ${ }^{1} \mathrm{H}$ lineshapes as those shown in Figure $4 \mathrm{a}$ and $4 \mathrm{~b}$, are obtained. Only the $\mathrm{C}(2) \mathrm{H}$ peaks are shown for clarity. With respect to these latter sites, and assuming influences to the chemical environments sensitive to only directly neighbouring groups, four possible permutations with repetitions of environments need to be considered, i.e., $\mathrm{C}(2) \mathrm{H}_{2}-\mathrm{C}(3) \mathrm{H}_{2}, \mathrm{C}(2) \mathrm{H}_{2}-\mathrm{C}(3) \mathrm{HD}, \mathrm{C}(2) \mathrm{HD}-\mathrm{C}(3) \mathrm{H}_{2}$ and $\mathrm{C}(2) \mathrm{HD}-\mathrm{C}(3) \mathrm{HD}$, for both proton and carbon sites. The numerical fits of the experimental spectra of Figure $4 \mathrm{a}$ and $4 \mathrm{~b}$ are performed assuming these four environments. Only ${ }^{1} \mathrm{~J}\left({ }^{13} \mathrm{C}-{ }^{2} \mathrm{H}\right)$ and ${ }^{3} \mathrm{~J}\left({ }^{1} \mathrm{H}-{ }^{1} \mathrm{H}\right)$ couplings are considered.

These two $\mathrm{CH}_{2}$ or $\mathrm{CHD}$ environments can be revealed in a ${ }^{1} \mathrm{H}$ spectrum by monitoring the integral values of the relevant resonances, with pure $\mathrm{CH}_{2}$ samples resulting in twice the integral values as compared to pure CHD samples. Moreover, the monitoring of these signal intensities for all different sites may cast light on the mechanism of the reaction itself and on the presence of preferred sites of reduction within the $\mathrm{Q}$ molecule. For instance, in the case of $\mathrm{NaBD}_{4} / \mathrm{H}_{2} \mathrm{O}$, assuming a nucleophilic attack of a $\mathrm{D}^{-}$anion to $\mathrm{C}(2)$, the atom with the lowest electron density, followed by $\mathrm{H}^{+}$attack on the electron-rich nitrogen atom, one should expect the presence of an NH signal and a C(2) $\underline{H D}$ of equal intensities in the ${ }^{1} \mathrm{H}$ NMR spectrum. 


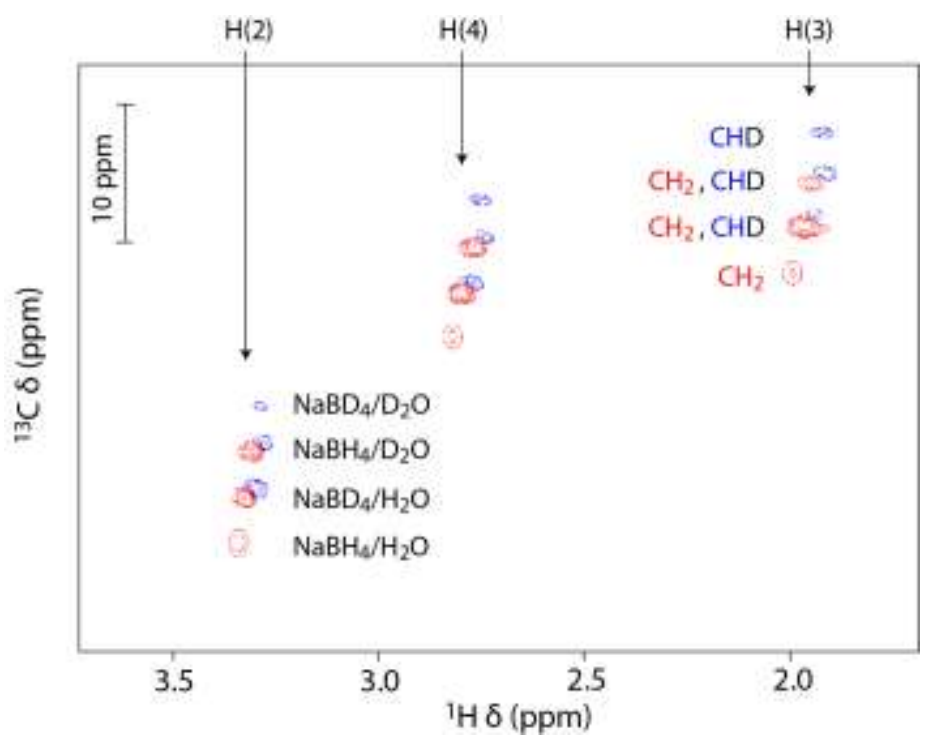

Fig. 3. Overlay of the aliphatic regions of phase-sensitive multiplicity-edited ${ }^{1} \mathrm{H}-{ }^{13} \mathrm{C}$ HSQC spectra of the four samples considered (in $\mathrm{CDCl}_{3}$ ). Red negative correlations indicate $\mathrm{CH}_{2}$ whereas blue positive correlations indicate CHD groups. The spectra are vertically displaced for clarity.

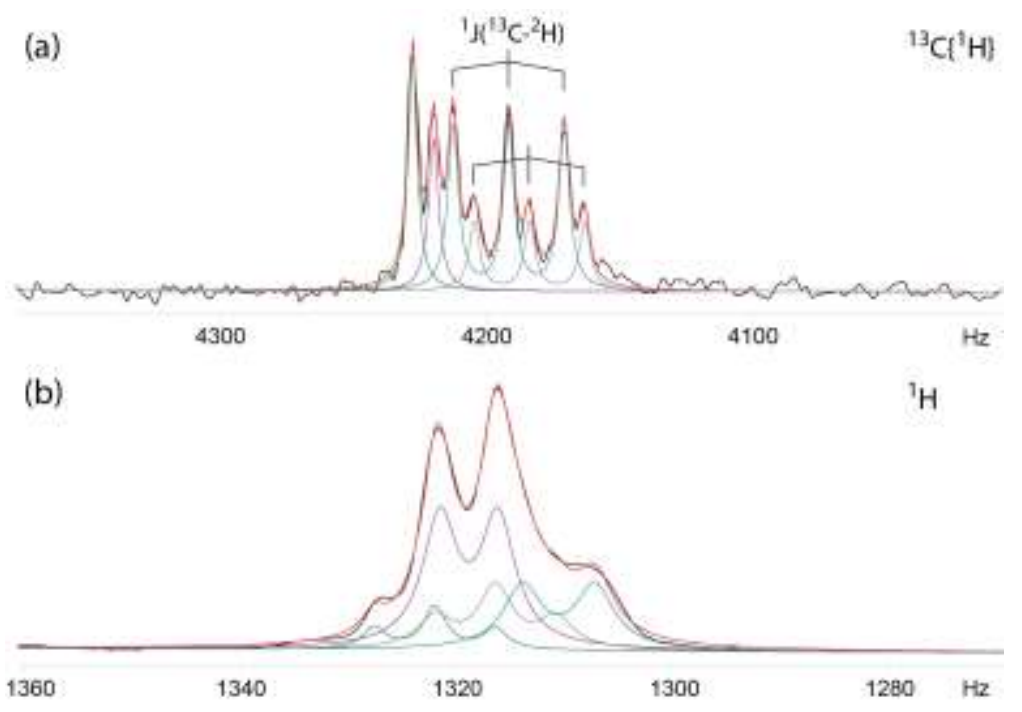

Fig. 4. (a) Numerical fit (red) of the $\mathrm{C}(2)$ region of a proton-decoupled ${ }^{13} \mathrm{C}$ NMR spectrum (black, in $\mathrm{CDCl}_{3}$ ) of THQ prepared with $\mathrm{NaBH}_{4} / \mathrm{D}_{2} \mathrm{O}$. The singlets at higher frequencies represent two proton-decoupled $\mathrm{CH}_{2}$ groups, whereas two 1:1:1 triplets at lower frequencies represent CHD groups. (b) Numerical fit (red) of the $\mathrm{H}(2)$ region of a ${ }^{1} \mathrm{H}$ spectrum (black, in $\mathrm{CDCl}_{3}$ ) of the same sample of (a) assuming one $\mathrm{C}_{2}-\mathrm{CH}_{2}$ as 1:2:1 triplet, one $\underline{\mathrm{C}}_{2}-\mathrm{CHD}$ as 1:1 doublet, one $\underline{\mathrm{C}} \underline{\mathrm{HD}}-\mathrm{CH}_{2}$ as 1:2:1 triplet and one $\underline{\mathrm{C}} \underline{\mathrm{HD}}-\mathrm{CHD}$ as 1:1 doublet, from 
higher to lower frequencies, respectively, and in agreement with the order of carbon resonances observed in (a). Heteronuclear ${ }^{2,3} \mathrm{~J}\left({ }^{1} \mathrm{H}-{ }^{2} \mathrm{H}\right)$ couplings are not included in (b), as the resulting splittings (ca. 1-2 Hz) are smaller than the homogeneous/inhomogeneous line width and are implicitly taken into account as line broadening by the numerical fit. For both ${ }^{13} \mathrm{C}$ and ${ }^{1} \mathrm{H}$ spectra, a low-frequency shift is observed as ${ }^{2} \mathrm{H}$ nuclei are progressively added. Numerical fits were performed with the DMfit software [48].

When integrals need to be measured accurately in NMR experiments, one has to make sure that signal averaging is done over experiments performed on fully relaxed systems. This is commonly accomplished by using a recycling delay $d_{1}$ between signal acquisitions of $d_{1}=5 \times T_{1}$. A subsequent measurement of the longitudinal relaxation time constant $T_{1}$ was therefore performed on the four samples considered in this study by means of an inversion-recovery experiment. The resulting $\mathrm{T}_{1}$ values are shown, as histogram, in Figure 5.

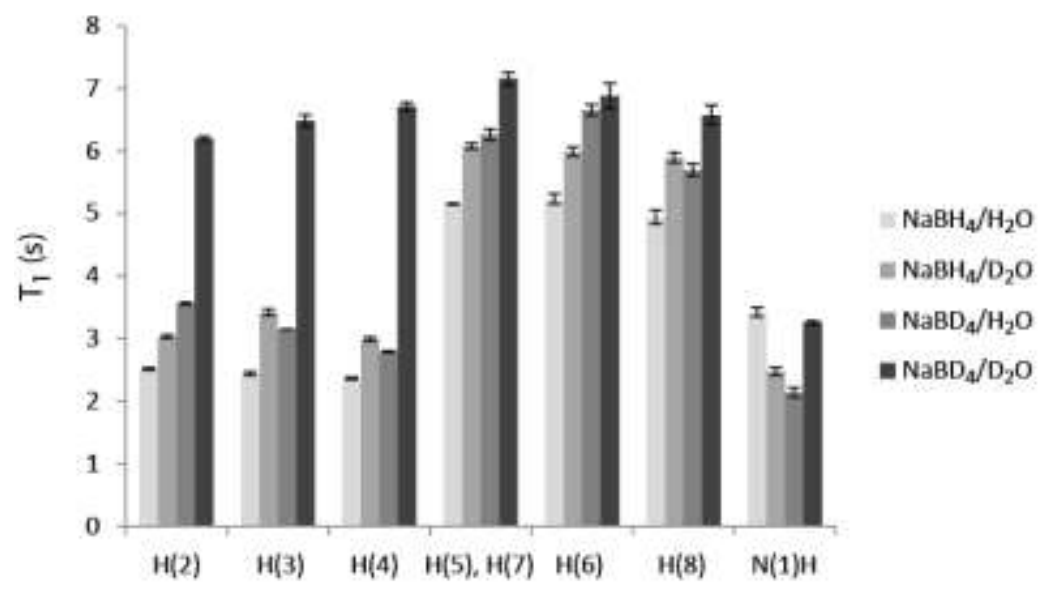

Fig. 5. Longitudinal relaxation time constants $T_{1}$ as measured on the four samples considered in this study with an inversion-recovery experiment. The error bars were calculated as $\pm \sigma$, with $\sigma$ being the standard deviation of the $T_{1}$ values produced by the numerical fits performed on eight data points as produced by the experiment.

It is clear that, as deuterium nuclei are progressively added in the system with the different reduction conditions, an increase of $\mathrm{T}_{1}$ values is observed as result of the consequent removal of proton-proton intramolecular homonuclear dipolar couplings which act as a source of relaxation. The longest $\mathrm{T}_{1}$ value for each case was used to estimate the appropriate recycling delay for ${ }^{1} \mathrm{H}$ NMR spectra of the four samples considered. In such a fashion, the integral values that obtained 
can be taken as an accurate measurement of the relative levels of deuteration at the various chemical sites within the THQ molecule. The corresponding results are shown in Figure 6 as histogram. The integrals were normalized to the value of the signal due to the overlapped $\mathrm{H}(5)$ and $\mathrm{H}(7)$ at $7.01 \mathrm{ppm}$.

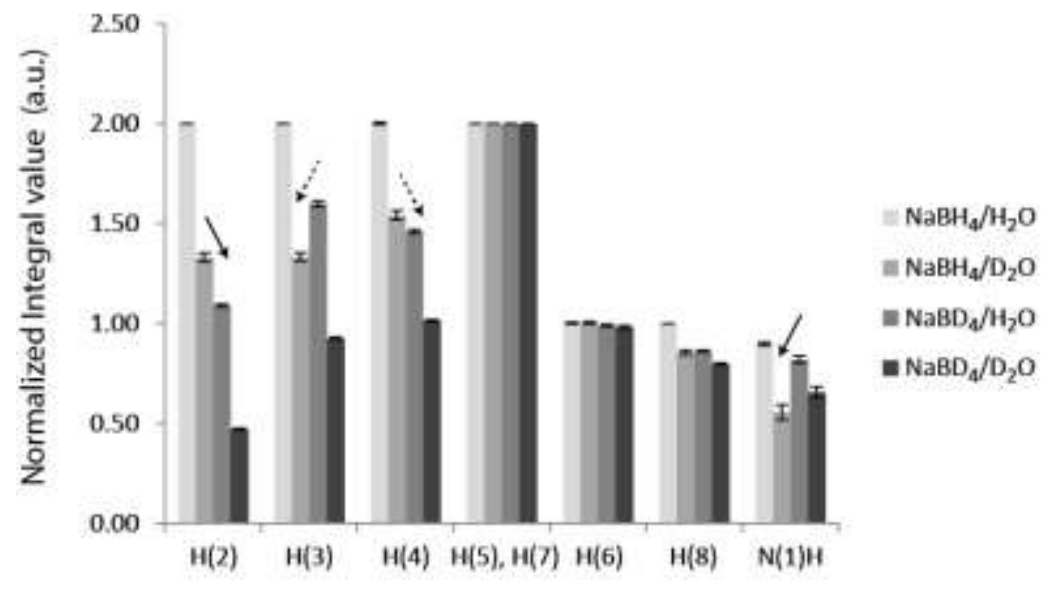

Fig. 6. Integral values of the various proton resonances of THQ for the various samples considered. The normalization has been performed with respect to the overlapped signals of $\mathrm{C}(5)$ and $\mathrm{C}(7)$. The error bars were calculated as $\pm \sigma$, with $\sigma$ being the standard deviation of the values produced by five independent integrations.

The catalytic quinoline reduction is quantitative, as one can clearly see for the $\mathrm{NaBH}_{4} / \mathrm{H}_{2} \mathrm{O}$ case, the measured integral values being 2 and 1 for aliphatic and aromatic protons, respectively, with deviations of only $1 \%$. The $\mathrm{NH}$ integral in this case is 0.95 . The $5 \%$ deviation from the ideal value of this site may be reasonably ascribed to the much larger line width as compared to all other resonances. When ${ }^{2} \mathrm{H}$ nuclei are involved in the reduction process, one observes a clear decrease of the integrals for the sites 2,3 and 4, with intensities $1<I<2$, representing a mixture of $\mathrm{CH}_{2}$ and $\mathrm{CHD}$ containing species, an ideal and quantitative reduction with only deuterium nuclei would yield $I=1$ for these sites. Similar results are obtained in the $\mathrm{NaBH}_{4} / \mathrm{D}_{2} \mathrm{O}$ and $\mathrm{NaBD}_{4} / \mathrm{H}_{2} \mathrm{O}$ cases. Interestingly, also the aromatic site 8 in the $C$-cycle undergoes a significant decrease in signal intensity, which clearly is the result of a $\mathrm{CH} \rightarrow \mathrm{CD}$ exchange/substitution. As only ${ }^{2} \mathrm{H}$ species are involved in the reaction for the $\mathrm{NaBD}_{4} / \mathrm{D}_{2} \mathrm{O}$ case, a further decrease in intensity is observed for all aliphatic sites, with $I<1$, indicating that $\mathrm{CD}_{2}$ species appear in the 
sample as a result of a $\mathrm{CHD} \rightarrow \mathrm{CD}_{2}$ process similar to that observed for site 8 . Possible exchanges in sites 5 and 7 cannot be monitored by this approach, since these resonances have been used as reference to calibrate all integral values. One may, however, assume that, if any exchange happens on these sites, it has to be very similar to that of site 6. As the integral of this latter seems to be substantially insensitive to the various experimental conditions explored in this study, we suggest that exchanges in sites 5, 6 and 7 may be ignored in this context. Therefore, the sites that appear to be particularly susceptible to reduction in the quinoline molecule are sites 2 , 3, 4 and surprisingly also site 8 , from higher to lower reactivity, respectively.

Because of the complications by the known slow H/D exchange between the $\mathrm{BH}_{4}{ }^{-}$anion and $\mathrm{D}_{2} \mathrm{O}$ (or the $\mathrm{BD}_{4}{ }^{-}$anion and $\mathrm{H}_{2} \mathrm{O}$ ) [44] and also by the observed $\mathrm{H} / \mathrm{D}$ exchange of the $\mathrm{C}-\mathrm{H}$ and $\mathrm{N}$ $\mathrm{H}$ functions in the THQ molecule (even in the $C$-cycle), the data do not allow unambiguous mechanistic considerations. Nevertheless, it is obvious that, in the most meaningful cases $\mathrm{NaBH}_{4} / \mathrm{D}_{2} \mathrm{O}$ and $\mathrm{NaBD}_{4} / \mathrm{H}_{2} \mathrm{O}$, all hydrogenated positions are partially deuterated, in the first case the degree of deuteration in $\mathrm{C}(2)$ is slightly lower than in the second case, but in the $\mathrm{N}(1)$ position this ratio is inversed (black arrows in Fig. 6), and a similar trend is observed for the positions C(4) and C(3) (dashed arrows in Fig. 6).

In silico computations of molecular properties can be very useful for the rationalization of experimental data. In particular, semi-empirical methods have been used with success in a variety of structural studies [49-51]. In this context, calculations of the net atomic charges associated to each nuclear site within both Q and THQ molecules were carried out at the PM7 semi-empirical level with the code MOPAC2012 and electrostatic potential surfaces were computed by means of the keyword ESP [52]. Furthermore, 1,2-dihydroquinoline (1,2-DHQ) was considered as a possible intermediate. The results are summarized in Fig. 7, where the net charges of Q, 1,2-DHQ and THQ are shown from $7 \mathrm{a}$ to $7 \mathrm{c}$, respectively. In Fig. $7 \mathrm{~d}-\mathrm{f}$, the corresponding electrostatic potential surfaces generated by these charges are illustrated. With respect to the Q molecule, the most positively charged carbon atom in the $\mathrm{N}$-cycle is, as expected, $\mathrm{C}(2)$, suggesting an initial attack of hydride anions to this position. The preferred site for a subsequence proton attack is the nitrogen atom. A second hydride attack on the $N$-cycle finds $\mathrm{C}(4)$ as preferred site, given the lower net negative charge as compared to $\mathrm{C}(3)$. It is also worth noting that the most positively charged proton on the $C$-cycle is $\mathrm{H}(8)$. This is in agreement with the experimental observation 
that this proton is also exchanged/substituted by deuterium in the $\mathrm{NaBD}_{4} / \mathrm{D}_{2} \mathrm{O}$ case. An alternative rationalization involves to the coordination of THQ and Q by N(1) to the Ru nanoparticle surface, exposing $\mathrm{H}(8)$ to oxidative addition to generate surface hydride, which may then undergo H/D exchange.

(a)

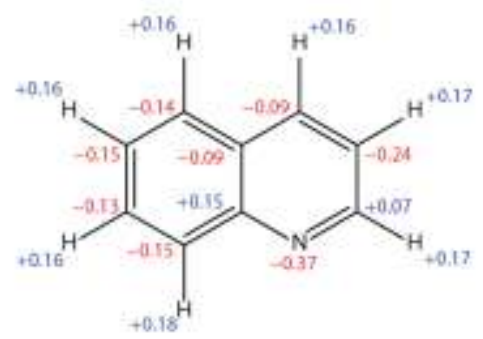

(b)

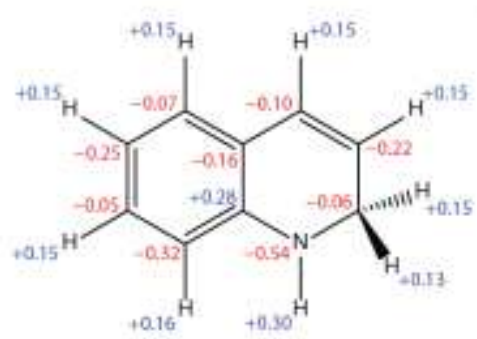

(c)

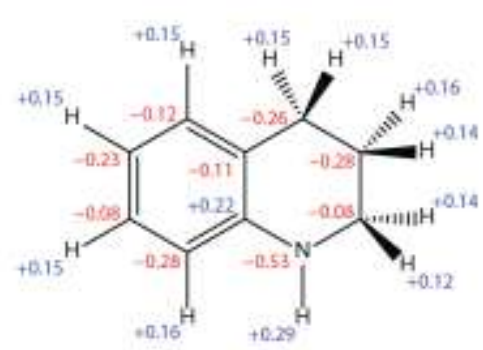

(d)

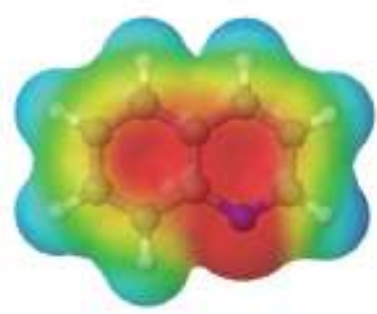

(e)

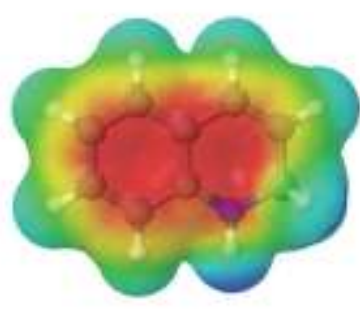

(f)

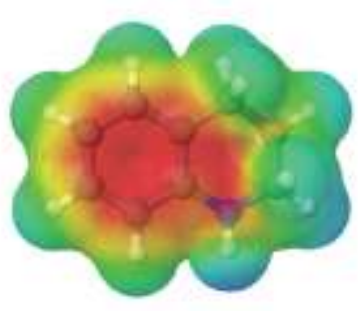

Fig. 7. Net atomic charges of the nuclear sites in Q, 1,2-DHQ and THQ molecules ( $a, b$ and $c$ ) along with the surfaces of the electrostatic potentials (d, e and f), plotted from $-0.1 \mathrm{~V}$ (red) to $+0.1 \mathrm{~V}$ (blue).

Although a homolytic hydrogenation mechanism by in situ generated $\mathrm{H}_{2}$ cannot completely be ruled out, a heterolytic hydrogenation by $\mathrm{H}^{-}$and $\mathrm{H}^{+}$seems to be in operation here, since the following conclusions are consistent with the experimental data: i) Sodium borohydride is not the single hydrogen source and water is not an innocent solvent; the hydrogen for the hydrogenation 
of the $\mathrm{N}$-cycle of the quinoline molecule comes from both $\mathrm{NaBH}_{4}$ and $\mathrm{H}_{2} \mathrm{O}$. ii) The hydrogenation seems to be accomplished by a transfer of a hydride $\left(\mathrm{H}^{-}\right)$from the borohydride anion and of a proton $\left(\mathrm{H}^{+}\right)$from the water molecule. iii) The hydride anion is more likely to attack at first the most electron-poor atom of the quinoline molecule $\mathrm{C}(2)$, while the proton is likely to attack then the most electron-rich atom of the quinoline molecule N(1). The following step of the reduction involves the attack of a $\mathrm{H}^{-}$species on $\mathrm{C}(4)$, then followed by a $\mathrm{H}^{+}$attack on $\mathrm{C}(3)$, in accordance with the analysis of the integral values of our isotope labeling study and with the net charges calculated for the different positions (Figure 7). This model is also in line with the observed $C$-cycle hydrogenation instead of the $N$-cycle hydrogenation in the case of 2phenylquinoline, where the $\mathrm{C}(2)$ position is blocked by a phenyl substituent (entry 13, Table 2).

\subsection{Catalyst recyclability}

The recyclability of nanoRu'@ hectorite was studied with the hydrogenation of $\mathbf{1}$ to $\mathbf{1 a}$ (entry 7, Table 1) as model. After a catalytic run, the catalyst was recovered by centrifugation and purified by washing with deionized $\mathrm{H}_{2} \mathrm{O}$ and ethyl acetate and dried in vacuo at room temperature for $12 \mathrm{~h}$. Then the recycled catalyst was used directly in the next catalytic run without reactivation. As depicted in Fig. 8, the conversion of 1 slightly declined from $99 \%$ to 95\% after 4 cycles, but the selectivity is maintained at 99\%. Transition electron microscopy (Fig. 2) shows that the clusters of ruthenium nanoparticles retain their spherical shape and the size of the nanoparticles stays within a narrow size distribution of 1.5-3 nm. Ruthenium leaching during the catalytic reactions was found by ICP-OES analysis to be inferior to $2 \mathrm{ppm}$. 


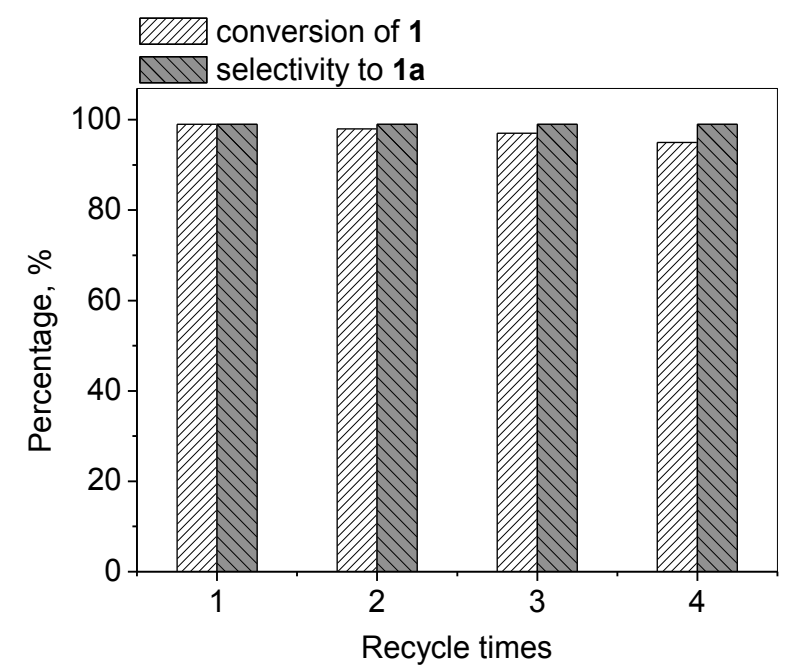

Fig. 8. Reactivity and selectivity of nanoRu'@ hectorite catalyst in recycling tests for the hydrogenation of $\mathbf{1}$ to $1 \mathrm{a}$ in water under atmospheric pressure at $60^{\circ} \mathrm{C}$ for $4 \mathrm{~h}$.

\section{Conclusions}

In summary, we report a simple method for preparing a new hectorite-supported ruthenium precatalyst, which has an exceptional catalytic activity and selectivity for the hydrogenation of the $N$-cycle of quinolines and analogues by sodium borohydride in aqueous media, mostly without pressure equipment. Isotope labelling studies demonstrate the participation of water in the hydrogenation reaction by providing protons. Transition electron microscopy shows the catalyst to contain metallic ruthenium nanoparticles agglomerated to spherical clusters intercalated in the hectorite clay (nanoRu'@hectorite). The catalyst can be recycled and reused for further catalytic runs.

The Energy Dispersive X-ray Spectroscopy (EDS) analysis of nanoRu'@hectorite and the ${ }^{1} \mathrm{H}$ NMR and ${ }^{13} \mathrm{C}$ NMR data can be found in the Supplementary Information.

\section{Acknowledgments}

Financial support of this work from Swiss National Science Foundation (SNSF) is gratefully acknowledged. B. S. is grateful to the China Scholarship Council (CSC) for a grant. We thank Dr. 
Mohammad Mehdi Dadras in CSEM for TEM analysis. We also thank the Johnson Matthey Research Center for a generous loan of ruthenium(III) chloride hydrate.

\section{References}

[1] V. Sridharan, P.A. Suryavanshi, J.C. Menendez, Chem. Rev. 111 (2011) 7157-7259.

[2] R. Omar-Amrani, A. Thomas, E. Brenner, R. Schneider, Y. Fort, Org. Lett. 5 (2003) 2311-2314.

[3] T. Kubo, C. Katoh, K. Yamada, K. Okano, H. Tokuyama, T. Fukuyama, Tetrahedron 64 (2008) $11230-11236$.

[4] K. Maruoka, T. Miyazaki, M. Ando, Y. Matsumura, S. Sakane, K. Hattori, H. Yamamoto, J. Am. Chem. Soc. 105 (1983) 2831-2843.

[5] C.H. Bartholomew, Appl. Catal. A: Gen. 212 (2001) 17-60.

[6] S. Nishimura, Handbook of Heterogeneous Catalytic Hydrogenation for Organic Synthesis, WILEY, New York, 2001.

[7] S.M. Lu, X.W. Han, Y.G. Zhou, J. Organomet. Chem. 692 (2007) 3065-3069 (and references cited therein).

[8] W.B. Wang, S.M. Lu, P.Y. Yang, X.W. Han, Y.G. Zhou, J. Am. Chem. Soc. 125 (2003) 1053610537.

[9] H. Zhou, Z. Li, Z. Wang, T. Wang, L. Xu, Y. He, Q.-H. Fan, J. Pan, L. Gu, A.S.C. Chan, Angew. Chem. Int. Ed. 47 (2008) 8464-8467.

[10] D. Ren, L. He, L. Yu, R.S. Ding, Y.M. Liu, Y. Cao, H.Y. He, K.N. Fan, J. Am. Chem. Soc. 134 (2012) 17592-17598.

[11] N. Hashimoto, Y. Takahashi, T. Hara, S. Shimazu, T. Mitsudome, T. Mizugaki, K. Jitsukawa, K. Kaneda, Chem. Lett. 39 (2010) 832-834.

[12] R. Rahi, M. Fang, A. Ahmed, R.A. Sánchez-Delgado, Dalton Trans. 41 (2012) 14490-14497.

[13] Y. Gong, P. Zhang, X. Xu, Y. Li, H. Li, Y. Wang, J. Catal. 297 (2013) 272-280.

[14] M. Campanati, A. Vaccari, O. Piccolo, J. Mol. Catal. A: Chem. 179 (2002) 267-272.

[15] M. Campanati, M. Casagrande, I. Fagiolino, M. Lenarda, L. Storaro, M.Battagliarin, A. Vaccari, J. Mol. Catal. A: Chem. 184 (2002) 287-292.

[16] M. Fang, N. Machalaba, R.A. Sánchez-Delgado, Dalton Trans. 40 (2011)10621-10632.

[17] L.M. Zhou, X.L. Qi, X.H. Jiang, Y.F. Zhou, H.Y. Fu, H. Chen, J. Colloid. Interface Sci. 392 (2013) 201-205.

[18] M. Fang, R.A. Sánchez-Delgado. J. Catal. 311 (2014) 357-368.

[19] F. Fache, Synlett 15 (2004) 2827-2829. 
[20] C. Michel, J. Zaffran, A.M. Ruppert, J. Matras-Michalska, M. Jędrzejczyk, J. Grams, P. Sautet, Chem. Commun. 50 (2014) 12450-12453.

[21] L. Zhang, X.Y. Wang, Y. Xue, X.J. Zeng, H. Chen, R.X. Li, S.L. Wang, Catal. Sci. Technol. 4 (2014) 1939-1948.

[22] H. Mao, C. Chen, X. Liao, B. Shi, J. Mol. Catal. A: Chem. 341 (2011) 51-56.

[23] H. Mao, J. Ma, Y. Liao, S.L. Zhao, X.P. Liao, Catal. Sci. Technol. 3 (2013) 1612-1617.

[24] M.M. Dell'Anna, V.F. Capodiferro, M. Mali, D. Manno, P. Cotugno, A. Monopoli, P. Mastrorilli, Appl. Catal. A: Gen. 481 (2014) 89-95.

[25] D. Marquardt, C. Vollmer, R. Thomann, P. Steurer, R. Mülhaupt, E. Redel, C. Janiak, Carbon 49 (2011) 1326-1332.

[26] R. Marcos Esteban, K. Schütte, D. Marquardt, J. Barthel, F. Beckert, R. Mülhaupt, C. Janiak, NanoStruct. Nano-Objects 2 (2015) 28-34.

[27] A. Meister, G. Meister, G. Süss-Fink, J. Mol. Catal. 92 (1994) L123-L126.

[28] G. Süss-Fink, B. Mollwitz, B. Therrien, M. Dadras, G. Laurenczy, A. Meister, G. Meister, J. Clust. Sci. 18 (2007) 87-95.

[29] G. Süss-Fink, F.-A. Khan, J. Boudon, V. Spassov, J. Clust. Sci. 20 (2009) 341-353.

[30] B. Sun, F.-A. Khan, A. Vallat, G. Süss-Fink, Applied Catal. A: Gen. 467 (2013) 310-314.

[31] M.M. Dell'Anna, G. Romanazzi, S. Intini, A. Rizzuti, C. Leonelli, A.F. Piccinni, P. Mastrorilli, J. Mol. Catal. A: Chem. 402 (2015) 83-91.

[32] K.H. Bergk, D. Woldt, unpublished. See D. Woldt, PhD Thesis, University of Halle-Wittenberg, Germany, 1988.

[33] G. Lagaly, H. Tributh, Ber. Dt. Tonmineralgruppe 86 (1996).

[34] W.L. Bragg, The diffraction of short electromagnetic wave by a crystal. Proc. Camb. Philos. Soc. (1913) 43-57.

[35] C.A. Schneider, W.S. Rasband, K.W Eliceiri, Nat. Methods 9 (2012) 671-675.

[36] J.J.P. Stewart, Stewart Computational Chemistry, Version 13.073W web: HTTP://OpenMOPAC.net.

[37] R.E. Grim, Clay mineralogy 4, Structure of Clay Minerals, Smectide Minerals, McGraw-Hill, USA, 1968.

[38] D. Astruc, Nanoparticles and Catalysis, WILEY-VCH, Weinheim, 2008.

[39] C.L. Kitchens, M.C. McLeod, C.B. Roberts, J. Phys. Chem. B 107 (2003) 11331-11338.

[40] J. Song, D. Kim, D. Lee, Langmuir 27 (2011) 13854-13860.

[41] B.S. Akpa, C. D’Agostino, L.F. Gladden, K. Hindle, H. Manyar, J. McGregor, R. Li, M. Neurock, N. Sinha, E.H. Stitt, D. Weber, J.A. Zeitler, D.W. Rooney, J. Catal. 289 (2012) 30-41.

[42] H.J. Wan, A. Vitter, R.V. Chaudhari, B. Subramaniam, J. Catal. 309 (2014) 174-184.

[43] R. Yang, S.G. Schulman, Luminescence 16 (2001) 129-133. 
[44] M. Hönel, F.W. Vierhapper, J. Chem. Soc., Perkin Trans. 1 (1980) 1933-1939.

[45] Y.P. Sun, H.Y. Fu, D.L. Zhang, R.X. Li, H. Chen, X.J Li, Catal.Commun. 12 (2010) 188-192.

[46] R.E. Mesmer, W.L. Jolly, Inorg. Chem. 1 (1962) 608-612.

[47] R.E. Davis, E. Bromels, C.L. Kibby, J. Am. Chem. Soc. 84 (1962) 885-892.

[48] D. Massiot, F. Fayon, M. Capron, I. King, S. Le Calvé, B. Alonso, J.O. Durand, B. Bujoli, Z.H. Gan, G. Hoatson, Magn. Reson. Chem. 40 (2002) 70-76.

[49] D. Carnevale, V. Del Amo, D. Philp, S.E. Ashbrook, Tetrahedron 66 (2010) 6238-6250.

[50] D. Carnevale, A.J. Perez Linde, G. Bauer, G. Bodenhausen, Chem. Phys. Lett. 580 (2013) 172-178.

[51] N. Salvi, J. Frey, D. Carnevale, M. Grätzel, G. Bodenhausen, Dalton Trans. 43 (2014) 6389-6395.

[52] B.H. Besler, K.M. Merz Jr., P.A. Kollman, J. Comp. Chem, 11 (1990) 431-439. 
Graphical abstract

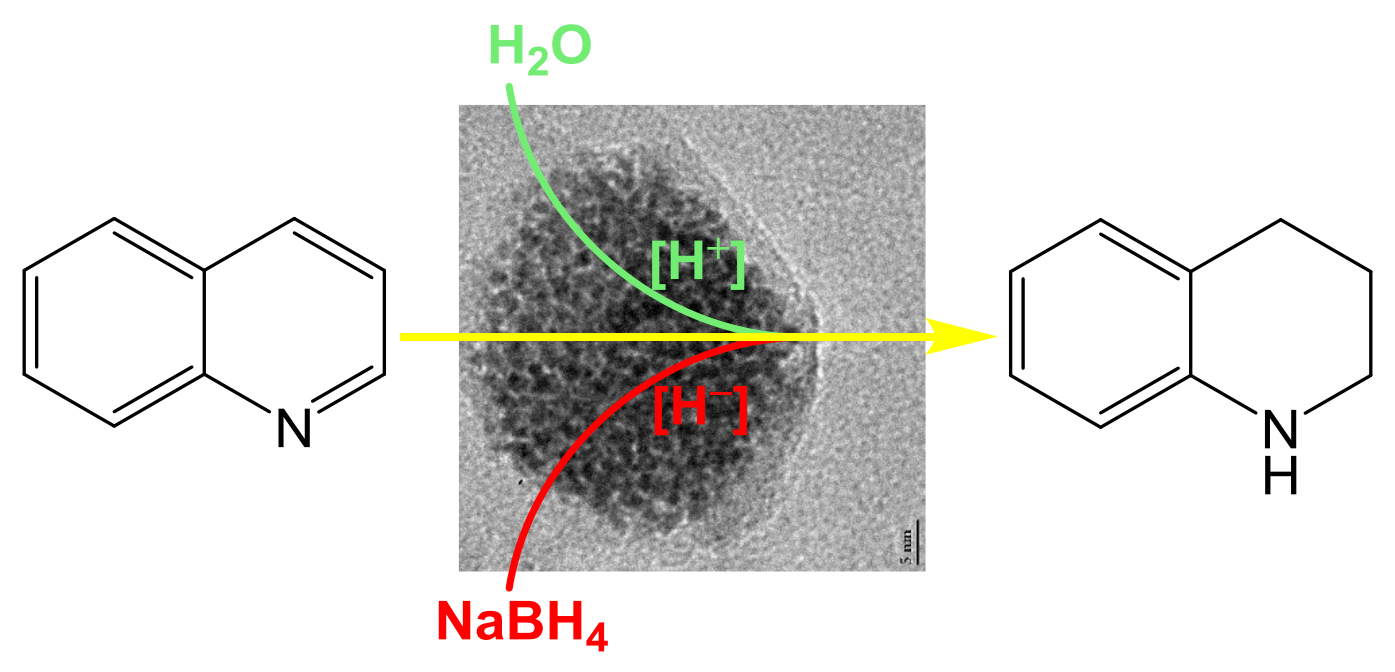

